\title{
Parameters of Hemodynamic Instability Measured by Transcranial Doppler in Patients Undergoing Carotid Endarterectomy and Carotid Angioplasty-Stent: Comparison Between Groups
}

\author{
Lorena Benavente Fernandez ${ }^{a}$, , Marta Suarez Pinilla ${ }^{a}$, Alberto Gil Garcia ${ }^{b}$, \\ Jose Maria Gutierrez ${ }^{c}$, Carlos H. Lahoz ${ }^{\text {a }}$, Sergio Calleja Puerta ${ }^{a}$
}

\begin{abstract}
Background: Carotid atheromatosis causes $15-20 \%$ of ischemic stroke. Interventional treatment is sometimes limited by the risk of reperfusion, stroke and other complications. A better knowledge of hemodynamic changes along the procedures could help to establish the treatment in each patient. We aimed to gain insight into this employing transcranial Doppler (TCD) monitoring and determine conditions with a higher risk of complications.
\end{abstract}

Methods: We prospectively recruited 53 patients with $\geq 70 \%$ cervical carotid stenosis or occlusion who underwent carotid angioplastystenting (CAS) (28 patients) or carotid endarterectomy (CEA) (25 patients). We performed TCD monitoring during the whole procedures.

Results: Frequency of reperfusion syndrome (RS) was similar in both procedures, but other complications were more common $(\mathrm{P}<0.001)$ in CEA. At baseline, hemodynamic reserve (HR) was correlated with asymmetry between mean flow velocity (MV) of middle cerebral arteries (MCAs) $(\mathrm{r}=-0.582 ; \mathrm{P}=0.003)$ and delayed systolic peak $(\mathrm{r}=$ $-0.44 ; \mathrm{P}=0.02$ ). Over $100 \%$ increase in MV after recanalization was associated with lower HR, but not to the RS. A more marked change in MV was associated with CAS procedure $(\mathrm{P}=0.081)$, lack of orthodromic flow in ophthalmic artery $(\mathrm{P}=0.013)$ and $\geq 95 \%$ carotid stenosis.

Conclusions: Baseline asymmetry between MCA MVs and subsequent increase in the latter is related to parameters of hemodynamic instability, such as critical stenosis, endovascular procedure and loss of orthodromic flow in the OF. However, MV alone is not a good predictor of RS, despite of baseline MVs asymmetry related to impaired $\mathrm{HR}$ and peak systolic delay. RS is equally frequent in CEA and CAS

Manuscript accepted for publication August 20, 2015

aDepartment of Neurology, Hospital Universitario Central de Asturias, Oviedo, Spain

bDepartment of Radiology, Hospital Universitario Central de Asturias, Oviedo, Spain

'Department of Vascular Surgery, Hospital Universitario Central de Asturias, Oviedo, Spain

${ }^{\mathrm{d} C o r r e s p o n d i n g ~ A u t h o r: ~ L o r e n a ~ B e n a v e n t e ~ F e r n a n d e z, ~ D e p a r t m e n t ~ o f ~ N e u r o l-~}$ ogy, Hospital Universitario Central de Asturias, C/Julian Claveria, s/n, 33006 Oviedo, Asturias, Spain. Email: lbf.benfer@gmail.com

doi: http://dx.doi.org/10.14740/jnr351w techniques, while other complications are more common in the former.

Keywords: Cerebral hemodynamics; Transcranial Doppler; Collaterals; Mean velocity asymmetry; Pulsatility index; Systolic delay; Endarterectomy; Carotid angioplasty-stent; Carotid revascularization

\section{Introduction}

Atherothrombotic stroke, mostly due to carotid atheromatosis, accounts for $15-20 \%$ of all ischemic strokes [1,2]. It often affects a large area of brain parenchima and entails a high morbi-mortality and dependence. Treatment of carotid atheromatosis was assessed in several trials (NASCET, ECST, ACAS, ACST) [3-6] by comparing medical and surgical approaches, although with important methodological differences, particularly involving quantification of carotid stenosis. NASCET and ECST established that surgery was better than medical approach in symptomatic, $>70 \%$ carotid stenoses if surgical risk was $\leq 6 \%$, while the last two concluded the same for asymptomatic stenoses with a $\leq 3 \%$ surgical risk. The landscape of possibilities expanded with the development of angiography and navigation systems with microcatheters and distal territory protection devices, which gave birth to a third option, the endovascular approach, whose efficacy and security have not been well established yet [7-15].

Revascularization approaches intend, on the one hand, to remove a plaque which has become a source of arterio-arterial embolisms and, on the other hand, to correct the hemodynamic deficit cause by a high-grade stenosis. Under normal conditions, brain autoregulation maintains the stability of cerebral blood flow despite a proximal stenosis, by means of progressive arteriolar vasodilation as cerebral perfusion pressure decreases. However, when adaptation limits are exceeded, cerebral blood flow can no longer be maintained, and this decrease is deemed predictive of stroke, being more frequent in symptomatic than asymptomatic stenosis [16-18].

Transcranial Doppler (TCD) is an ultrasonographic technique employed to examine intracranial arteries [19]. It has several applications, including the calculation of vasoreactivity, microemboli monitoring and recording of revascularization procedures, and it is useful to explore the pathogenic mechanisms of stroke [20-22]. 


\begin{tabular}{|l|l|}
\hline Breath holding index & BHI $=($ final V - initial V $) /$ initial V x 100/second \\
\hline Systolic peak flow delay & FA $=(\mathrm{SV}-\mathrm{DV}) /$ time \\
\hline Mean velocity & $\mathrm{MV}=(\mathrm{SV}+2 \mathrm{DV}) / 3$ \\
\hline Pulsatility index & $\mathrm{PI}=(\mathrm{SV}-\mathrm{DV}) / \mathrm{MV}$ \\
\hline
\end{tabular}

Figure 1. Hemodynamic parameter forms. FA: flow acceleration; SV: systolic velocity; DV: diastolic velocity; MV: mean velocity.

We aim to contribute to the knowledge of the brain hemodynamic along carotid revascularization procedures by monitoring flows in MCA and registering microembolic signals employing TCD. We tried to compare two different modalities of intervention and to generate more data about mechanisms that take place along these procedures. We also aim to study Doppler ability to detect hemodynamic changes and embolizations, and clinical consequences derived from both techniques, not only these related to the reperfusion syndrome (RS), but those derived from the techniques themselves. We tried to define which moments in each procedure imply a higher hemodynamic repercussion and risk of embolization, depending on the type of revascularization technique, and to know if there are special features in case of employing distal protection devices or revascularizating occlusive carotid, and also taking into account clinical features of patients and their influence on revascularization method assortment.

\section{Methods and Material}

\section{Patient selection and therapeutic groups}

This is a prospective observational study including 53 patients with a $\geq 70 \%$ cervical carotid stenosis or occlusion, symptomatic or not, who underwent a revascularization procedure between March 2007 and June 2008. Carotid occlusion patients were included on behalf of a high clinical severity despite of the best medical treatment. Of these patients, 25 were treated with CEA and 28 with CAS. The decision to intervene and the specific modality were up to the physicians in charge of each patient. The only exclusion criterion was the technical limitation for ultrasound monitoring due to absence of bone window.

Analysis is started with the descriptive study of demographic data. But we also split the sample into two groups, according to the interventional procedure, and both therapeutic groups, CEA and CAS, were compared according to their demographic, epidemiological and clinical features and neuroimaging findings, as well as to the hemodynamic values registered during TCD procedure monitoring.

\section{TCD monitoring}

Regarding hemodynamic parameters, we assessed breath hold- ing index (BHI), i.e. brain vasoreactivity determined by the Apnea test as a measure of hemodynamic reserve, delay of systolic peak or flow acceleration, collaterals and MV/pulsatility index (PI) asymmetry between both MCAs before, during and after the intervention, as well as their changes between the different stages of the procedure. Calculation formulas are depicted in online Fig. 1, included in data supplement.

TCD monitoring was conducted either in the vascular surgery or the neuroradiology operating room. Portable TCD devices with a $2 \mathrm{MHz}$ transduction probe and multichannel registering were used (SONARA; Cardinal Health, NeuroCare, Madison, WI, USA, Software 005.517 version, and SONARA; Cardinal Health, NeuroCare, Madison, WI, USA, Software 005.525 version). A frame attachment was employed to avoid changes in angulation or motion artifacts. Such frame was placed after anesthetic induction or diagnostic arteriography, without interfering in any case with the procedures. Monitoring of both MCAs was performed at a depth of $50-55 \mathrm{~mm}$ through the temporal bone window.

The whole procedures were monitored, but several key stages were defined for the appraisal of hemodynamic changes and/or microemboli generation, according to the results of a pilot study including three patients of each therapeutic group. In CEA, such moments were dissection of the artery, clamping and its release, and hemostasis. In CAS, they were the placement of the navigation catheter and the distal protection device, angioplasty, stent placement and its opening, withdrawal of navigation systems and angiographic series after the procedure. A semiquantitative scale of microemboli generation was created: no MES, < 5 MES; 5 - 10 MES; 10 - 25 MES; moderate: $>25$ MES when they still can be spotted one by one and do not erase the spectral wave; shower: numerous MES which cannot be independently spotted but still not erase the spectral wave; curtain: countless MES surpassing and erasing the spectral wave.

\section{Statistical analysis}

Statistical analysis was performed with the free distribution software R.2.10 (www.r-project.org). Quantitative variables were characterized by either the mean and standard deviation or the median, minimum and maximum values depending on whether they were normally distributed or not. The $95 \%$ confidence intervals are also reported for the most relevant variables. For categorical variables, absolute and relative frequen- 
Table 1. Epidemiologic and Clinical Characteristics

\begin{tabular}{|c|c|c|c|}
\hline & CEA, n (\%) & CAS, n (\%) & $\mathbf{P}$ \\
\hline Sex, male, n (\%) & $20(80 \%)$ & $25(89 \%)$ & \\
\hline Age, mean \pm standard deviation & $68.1 \pm 7.9$ & $70.8 \pm 10.3$ & \\
\hline \multicolumn{4}{|l|}{ HT } \\
\hline No & $6(24 \%)$ & $7(26 \%)$ & 0.80 \\
\hline Control HT & $15(60 \%)$ & $17(60 \%)$ & 0.80 \\
\hline Non-control HT & $4(16 \%)$ & $4(14 \%)$ & 0.50 \\
\hline \multicolumn{4}{|l|}{ Diabetes mellitus } \\
\hline No & $15(60 \%)$ & $17(60 \%)$ & 0.80 \\
\hline Control DM & $9(36 \%)$ & $8(29 \%)$ & 0.70 \\
\hline Non-control DM & $1(4 \%)$ & $3(11 \%)$ & 0.30 \\
\hline \multicolumn{4}{|l|}{ Dyslipemia } \\
\hline No & $12(48 \%)$ & $21(75 \%)$ & 0.04 \\
\hline Control DL & $12(48 \%)$ & $6(21 \%)$ & 0.04 \\
\hline Non-control DL & $1(4 \%)$ & $1(4 \%)$ & 0.70 \\
\hline \multicolumn{4}{|l|}{ Chronic lower limb ischemia } \\
\hline No & $20(80 \%)$ & $25(89 \%)$ & 0.20 \\
\hline Yes & $5(20 \%)$ & $3(11 \%)$ & \\
\hline \multicolumn{4}{|l|}{ Ischemic heart disease } \\
\hline No & $17(68 \%)$ & $19(68 \%)$ & 0.90 \\
\hline Angor & $4(16 \%)$ & $5(18 \%)$ & 0.50 \\
\hline $\mathrm{AMI}>6 \mathrm{~m}$ & $4(16 \%)$ & $4(14 \%)$ & 0.50 \\
\hline $\mathrm{AMI}<6 \mathrm{~m}$ & $0(0 \%)$ & $0(0 \%)$ & \\
\hline \multicolumn{4}{|l|}{ Arrhythmias } \\
\hline No & $22(88 \%)$ & $26(92 \%)$ & 0.40 \\
\hline $\mathrm{AF}$ & $3(12 \%)$ & $1(4 \%)$ & 0.30 \\
\hline $\mathrm{PM}$ & $0(0 \%)$ & $0(0 \%)$ & \\
\hline Others & $0(0 \%)$ & $1(4 \%)$ & \\
\hline \multicolumn{4}{|l|}{ Cardiomyopathy } \\
\hline No & $25(100 \%)$ & $24(86 \%)$ & 0.05 \\
\hline Dilated & $0(0 \%)$ & $4(14 \%)$ & \\
\hline Hypertrophy & $0(0 \%)$ & $0(0 \%)$ & \\
\hline Other & $0(0 \%)$ & $0(0 \%)$ & \\
\hline \multicolumn{4}{|l|}{ Valvular disease } \\
\hline No & $23(92 \%)$ & $27(96 \%)$ & 0.40 \\
\hline $\mathrm{AO}$ & $0(0 \%)$ & $1(4 \%)$ & \\
\hline MI & $1(4 \%)$ & $0(0 \%)$ & \\
\hline Several & $1(4 \%)$ & $0(0 \%)$ & \\
\hline \multicolumn{4}{|l|}{ Cardiovascular disease } \\
\hline No & $25(100 \%)$ & $27(96 \%)$ & 0.50 \\
\hline Systemic venous thrombosis & $0(0 \%)$ & $1(4 \%)$ & \\
\hline \multicolumn{4}{|l|}{ Systemic prothrombotic disease } \\
\hline No & $23(92 \%)$ & $27(96 \%)$ & 0.40 \\
\hline Hematologic diseases & $2(8 \%)$ & $1(4 \%)$ & \\
\hline \multicolumn{4}{|l|}{ Neoplasm } \\
\hline No & $24(96 \%)$ & $21(74 \%)$ & 0.03 \\
\hline Yes & $1(4 \%)$ & $7(26 \%)$ & \\
\hline
\end{tabular}


Table 2. Characterization of Carotid Revascularized Stenosis

\begin{tabular}{llll}
\hline & CEA, n (\%) & CAS, n (\%) & P \\
\hline Symptomatic stenoses, n (\%) & $13(52 \%)$ & $23(82.1 \%)$ & 0.02 \\
Left side (n) & 17 & 19 & 0.009 \\
Delay time (n symptomatic) (days) mean, median (rank) & $13,59.62,23(7-210)$ & $23,24.43,18(7-90)$ & 0.01 \\
Contralateral significant stenoses (n) & 11 & 24 & 0.004 \\
Homolateral high-grade stenoses & 9 & 11 & 0.028 \\
Reperfusion syndrome & $2(8 \%)$ & $4(15 \%)$ & 0.674 \\
Other complications & $21(84 \%)$ & $5(18 \%)$ & $<0.001$ \\
\hline
\end{tabular}

cies were employed.

For comparisons between groups, either parametric (Student's $t$, ANOVA) or non-parametric tests (Mann-Whitney U, Kruskal-Wallis) were employed on quantitative variables depending on Kolmogorov-Smirnov test for normality with Lilliefors correction. For categorical variables, $\mathrm{X}^{2}$ test with exact significance was used.

Pearson's coefficient was employed to assess bivariate correlation between continuous variables, such as percent MV asymmetry and percent change in ipsilateral MV after procedure. A visual exploration of the scatter plot allows distinguishing two separate groups of patients. The relationship of the aforementioned variables in each of the groups was analyzed by means of a linear regression.

Cut-off point for statistical significance was $\mathrm{P}<0.05$ in all cases.

\section{Results}

\section{Demographic and clinical features: differences between CEA and CAS groups}

Most patients in the sample were male, with a similar prevalence of vascular risk factors in both therapeutic groups, CEA $(80 \%)$ and CAS (89\%). Although mean age was also similar, values were more disperse in the CAS group, but non-significantly (CAS: $70.8 \pm 10.3$ (46 - 86); CEA: $68.1 \pm 7 . ;(54$ - 80)). Detailed information on demographic and clinical features is depicted in Table 1. More left carotid stenoses were treated, regardless of the technique. Asymptomatic stenoses were more common in the CEA group. This group also had a longer delay to intervention from the moment of symptoms. Contralateral and critical stenoses were more frequent in the CAS group. Although the latter are deemed a risk factor for the occurrence of RS [23], this was equally frequent in both groups, while other complications are more frequent in the CEA group. All of these characteristics are shown in Table 2.

As for the situation of brain hemodynamics before revascularization, it was similar for both groups, regarding MV and PI asymmetry between both MCAs and brain hemodynamic reserve (BHR), except for collateral vessels and intracranial signs of contralateral carotid stenoses, which were more frequent in the CAS group (Table 3).

\section{Hemodynamics at baseline and after revascularization}

As for other differences between CEA and CAS groups, on baseline TCD, there were more functional collateral vessels $(P=0.04)$ and more contralateral stenoses $(P=0.01)$ in the latter group. MV, PI and hemodynamic reserve were similar in both. Regardless of the differential hemodynamic conditions at baseline, RS was equally prevalent in both groups, while other complications were more frequent in the CEA group ( $\mathrm{P}$ $<0.001)$.

\section{BHR}

BRH shows a negative correlation with the degree of carotid stenosis and the asymmetry between MV in both MCAs (Pearson's coefficient correlation $(\mathrm{PCC})=-0.582, \mathrm{P}=0.003 ; \mathrm{PCC}=$ $-0.44, \mathrm{P}=0.02$, respectively) (Fig. 2).

Among patients with an impaired hemodynamic reserve $(\mathrm{BHI}<1.3 \pm 0.6$, or velocity increase $<20 \%$ ) [22], $>100 \%$ increase in MCA MV occurred after revascularization. However, this increase was not associated with the occurrence of RS.

\section{Systolic peak delay}

In the ipsilateral MCA, systolic peak delay, which was not related to the degree of carotid stenosis $(\mathrm{P}=0.6)$, immediately disappeared after the intervention in $90 \%$ of cases, especially in patients with a greater increase in MCA pulsatility after recanalization $(\mathrm{P}=0.03)$.

Conversely, in the MCA contralateral to the intervention, systolic peak delay did show association with the degree of contralateral carotid stenosis $(\mathrm{P}=0.02)$ and a negative correlation with ipsilateral stenosis $(\mathrm{P}<0.01)$ and baseline MCA PI asymmetry $(\mathrm{PCC}=-0.540 ; \mathrm{P}<0.001)$.

\section{Collateral vessels}

The number of permeable collaterals was associated with the degree of carotid stenosis $(\mathrm{P}=0.03)$. Reverse flow through the ophthalmic artery was also associated to the number of permeable collaterals $(\mathrm{P}<0.001)$ and the existence of a contralateral 
Table 3. TCD Hemodynamic Parameters in Both Groups

\begin{tabular}{|c|c|c|c|}
\hline & CEA, median (min - max) & ASC, median (min - max) & $\mathbf{P}$ \\
\hline MV asymmetry between MCA ( $\%$ dif.) & $16(-45-+65)$ & $21.5(-62-+68)$ & 0.40 \\
\hline PI asymmetry between MCA (\% dif.) & $16(-25-+62)$ & $17(-45-+71)$ & 0.90 \\
\hline \multicolumn{4}{|l|}{ Systolic delay } \\
\hline Homolateral (s) & $0.12(0.05-0.20)$ & $0.12(0.05-0.21)$ & 0.50 \\
\hline Contralateral (s) & $0.06(0.04-0.23)$ & $0.06(0.03-0.18)$ & 0.70 \\
\hline Contralateral & $36(20-70)$ & $35.30(12-98)$ & 0.90 \\
\hline \multicolumn{4}{|l|}{ Hemodynamic reserve $(\mathrm{BHI})$} \\
\hline Homolateral & $0.5(0.2-1.2)$ & $0.5(0.3-1.7)$ & 0.40 \\
\hline Contralateral & $0.9(0.6-1.5)$ & $1.05(0.3-2.4)$ & 0.50 \\
\hline \multicolumn{4}{|l|}{ No. collaterals (no ophthalmic) } \\
\hline 0 collaterals & $2(15 \%)$ & $3(11 \%)$ & 0.50 \\
\hline 1 collaterals & $8(62 \%)$ & $9(35 \%)$ & 0.20 \\
\hline 2 collaterals & $3(23 \%)$ & $7(27 \%)$ & 0.50 \\
\hline 3 collaterals & $0(0 \%)$ & $7(27 \%)$ & 0.04 \\
\hline \multicolumn{4}{|l|}{ Other findings TCD } \\
\hline No & $16(89 \%)$ & $13(52 \%)$ & 0.05 \\
\hline Contralateral stenosis & $0(0 \%)$ & $7(28 \%)$ & 0.01 \\
\hline VB proximal stenosis & $1(6 \%)$ & $4(16 \%)$ & 0.20 \\
\hline
\end{tabular}

\%dif.: \% of difference between both CMA MV; s: seconds; \%MV: \% of change in MV; BHI: breath holding index.

$\geq 70 \%$ carotid stenosis $(\mathrm{P}=0.049)$.

\section{MV and PI asymmetries before and after revascularization}

Baseline MV and PI asymmetries were positively correlated $(\mathrm{PCC}=0.376 ; \mathrm{P}=0.008)$, as were both $\mathrm{MV}$ and $\mathrm{PI}$ asymmetries before and after intervention $(\mathrm{PCC}=0.699 ; \mathrm{P}<0.001$ for $\mathrm{MV}$; $\mathrm{PCC}=0.507$; $\mathrm{P}=0.001$ for PI) (Fig. 3).

The only exception was observed in patients with preocclusive stenoses $(\geq 95 \%)$, where MV asymmetry before and after revascularization showed an inverse correlation $(\mathrm{P}=0.05)$, leading to a higher percent change after the procedure.

PI asymmetry before $(\mathrm{P}<0.001)$ and after $(\mathrm{P}=0.02)$ revascularization was lower in patients with $\geq 70 \%$ contralateral carotid stenosis.

A visual inspection of the scatter plot depicting the relationship between percent MV asymmetry and percent MV change after the intervention shows two clearly separate groups of patients. The one with a more dramatic change is nearly significantly related to the CAS technique $(\mathrm{P}=0.081)$, to the lack of an orthodromic ophthalmic artery, particularly for changes of $\mathrm{MV} \geq 40 \%(\mathrm{P}=0.013)$ and to a preocclusive carotid stenosis $(\mathrm{P}=0.002)($ Fig. 4$)$.

\section{Microembolic signals record}

Microemboli monitoring was conducted during the whole procedures, analyzing their patterns in the key moments in which they tended to cluster. Table 4 shows details of the matter.

Concerning CEA, during carotid dissection and clamping scarce embolic signals were registered only in $16 \%$ and $12.5 \%$ of patients, respectively. However, the clamping release was associated with a massive generation of MES (moderate, shower or curtain pattern $)$ in $70.8 \%$ of patients $(\mathrm{P}=0.003$; OR $=2.45$ ). Handling of the vessels also promoted MES, albeit mostly in mild patterns $(6.5 \% ; \mathrm{P}=0.06$; OR $=1.7)$. As for CAS, all preselected key moments were associated with MES: navigation with catheters $(\mathrm{P}<0.001$; $\mathrm{OR}=13.29)$; balloon swelling before $(\mathrm{P}<0.001 ; \mathrm{OR}=6.14)$ and after $(\mathrm{P}<0.001$; $\mathrm{OR}=4.80)$ stent placement. But the moments associated with a massive release of MES are opening of the distal protection device $(70 \%$ of patients, $\mathrm{P}=0.006$; $\mathrm{OR}=2.3)$, deflating of the balloon before $(\mathrm{P}<0.001 ; \mathrm{OR}=4.56)$ and after $(67 \%$; $\mathrm{P}$ $=0.02 ; \mathrm{OR}=2.03)$ stent placement and opening of the stent 

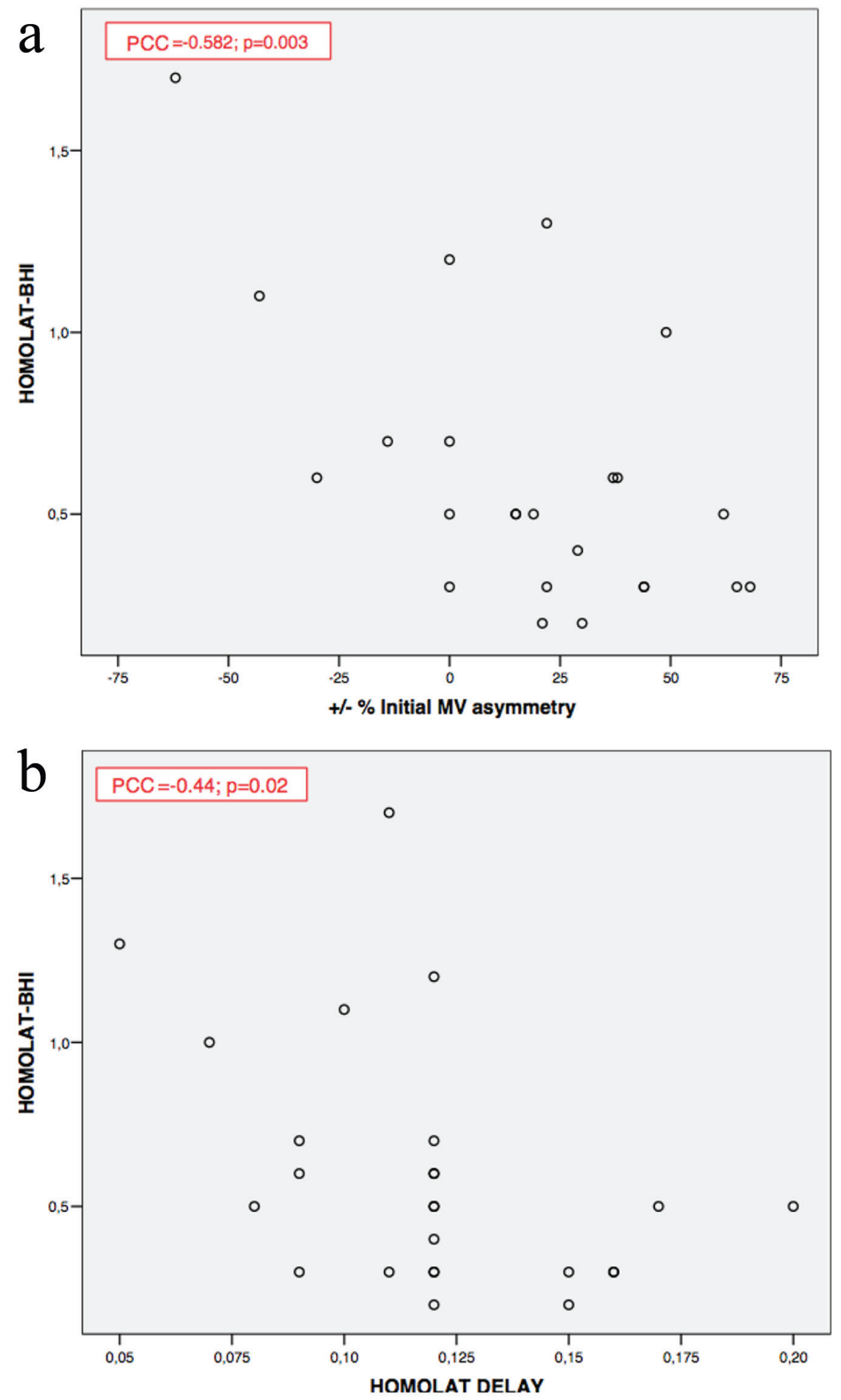

Figure 2. (a, b) Brain hemodynamic reserve correlations. Homolat-BHI: homolateral breath holding index; MV: mean velocity; Homolat delay: delay in flow acceleration; PCC: Pearson's coefficient correlation. 

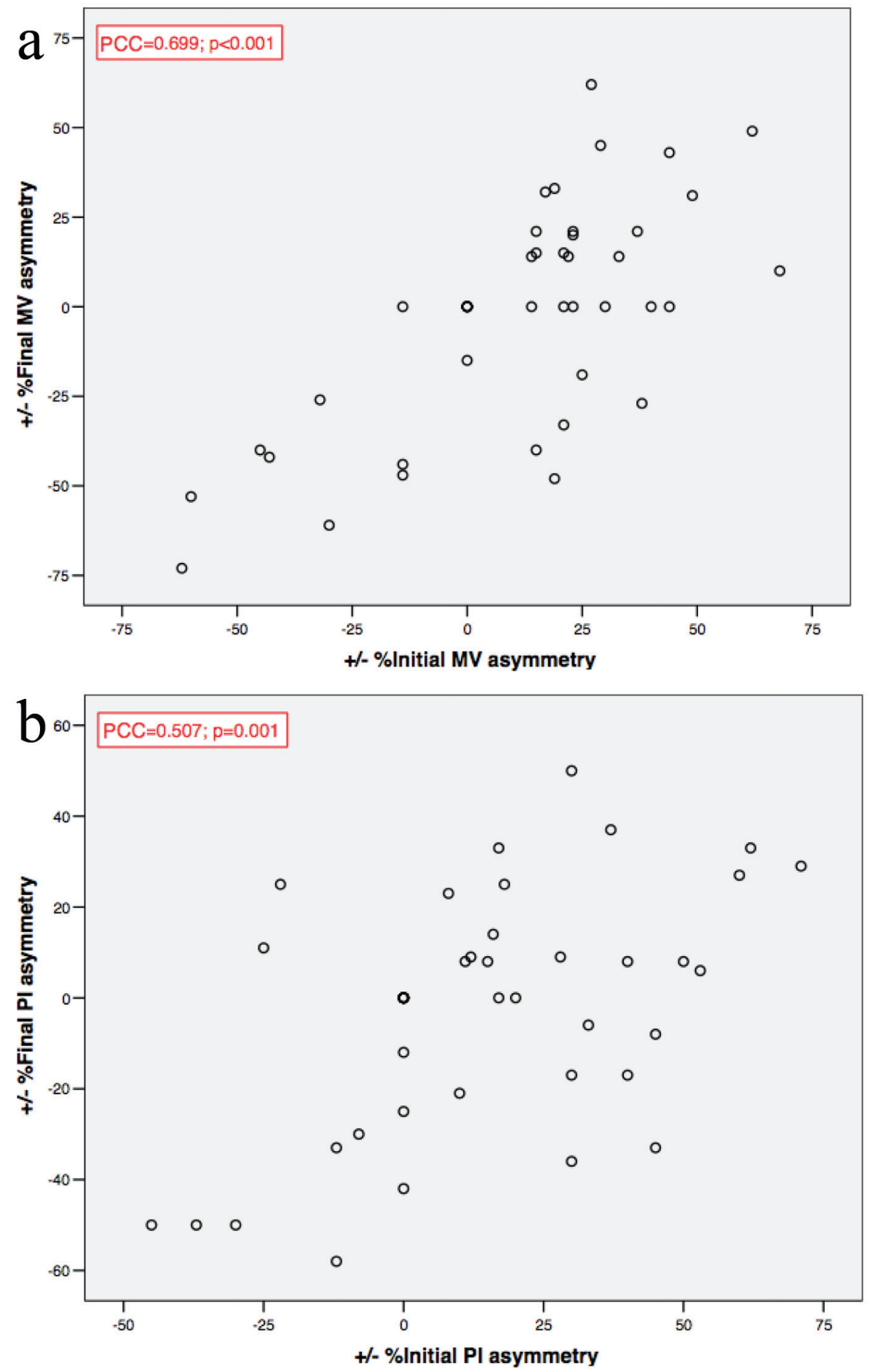

Figure 3. $(a, b, c) M V$ and PI asymmetries correlations. MV: mean velocity; PI: pulsatility index; PCC: Pearson's coefficient correlation. 


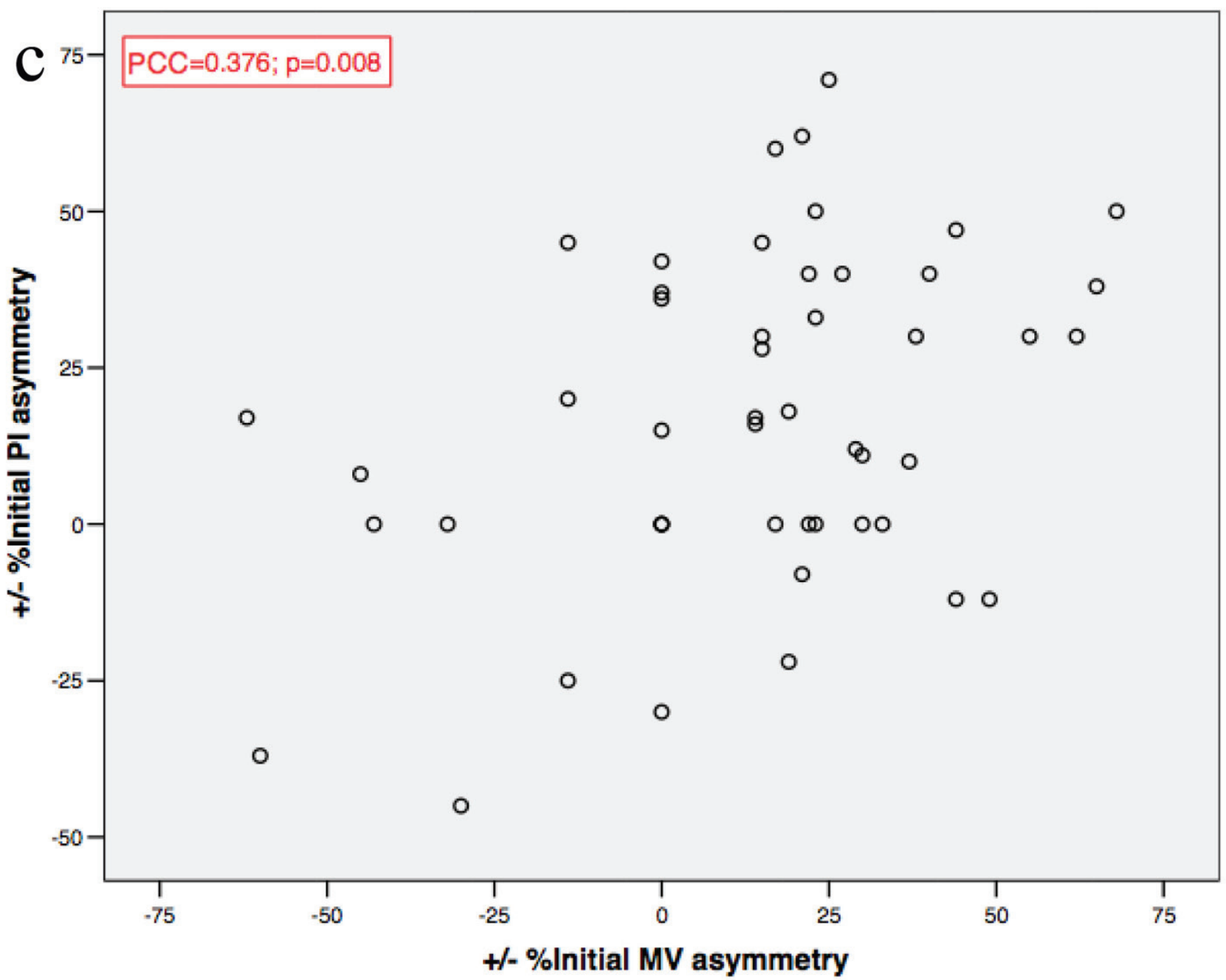

Figure 3. $(a, b, c) M V$ and PI asymmetries correlations. MV: mean velocity; PI: pulsatility index; PCC: Pearson's coefficient correlation. - (continued)

Table 4. Percentage of Patients With MES Patterns Register by TCD in Different Moments of CEA and CAS

\begin{tabular}{llllllll}
\hline MES patients \% & $\mathbf{0}$ & $\mathbf{<}$ & $\mathbf{5 - 1 0}$ & $\mathbf{1 0 - 2 5}$ & Moderate & Shower & Curtain \\
\hline Dissection & 84 & 16 & 0 & 0 & 0 & 0 & 0 \\
Clamp & 87.5 & 8.3 & 4.2 & 0 & 0 & 0 & 0 \\
Clamp release & 8.3 & 0 & 4.2 & 16.7 & 16.7 & 45.8 & 8.3 \\
Handling & 37.5 & 20.8 & 12.5 & 16.7 & 8.3 & 4.2 & 0 \\
Navigators & 7.1 & 28.6 & 14.3 & 28.6 & 21.4 & 0 & 0 \\
Filter & 0 & 30 & 0 & 0 & 40 & 20 & 10 \\
Swell_1 & 13.6 & 18.3 & 13.6 & 13.6 & 27.3 & 13.6 & 0 \\
Deflate_1 & 0 & 4.5 & 4.5 & 9.2 & 22.8 & 54.5 & 4.5 \\
Stent & 3.9 & 0 & 0 & 7.7 & 7.7 & 61.5 & 19.2 \\
Swell_2 & 16.7 & 20.8 & 29.2 & 8.3 & 20.8 & 4.2 & 0 \\
Deflate_2 & 8.3 & 0 & 4.3 & 20.8 & 33.3 & 33.3 & 0 \\
\hline
\end{tabular}



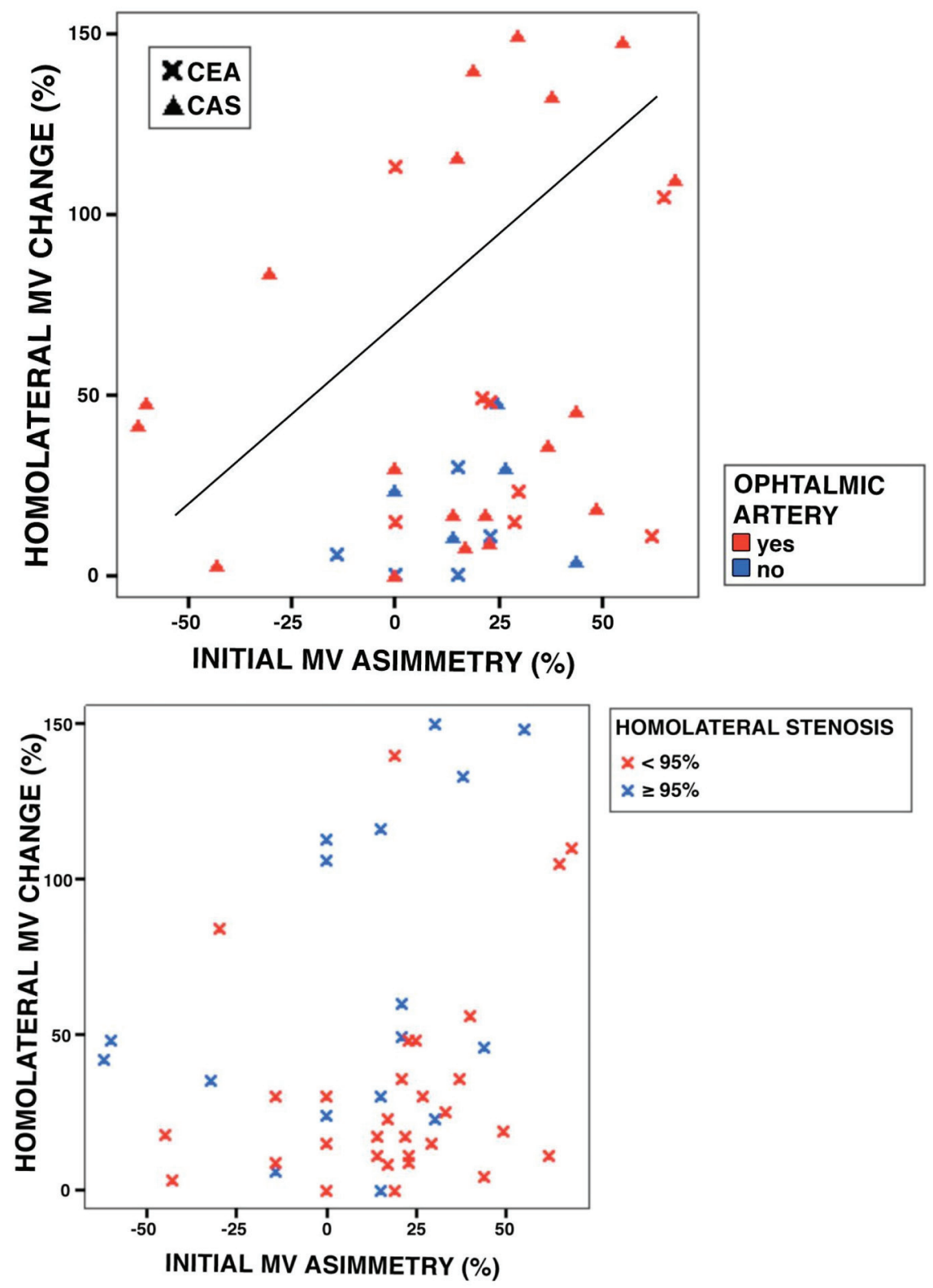

Figure 4. $(a, b)$ Groups of patients according to percent MV asymmetry and percent MV change after the intervention. MV: mean velocity; CEA: carotid endarterectomy; CAS: carotid angioplasty-stenting.

$(88.4 \% ; \mathrm{P}<0.001 ; \mathrm{OR}=7.33)$.

With respect to endovascular procedures, MES occurrence was analyzed according to whether a distal protection device was employed. Its opening was associated with MES generation $(\mathrm{P}<0.000001)$, which reached a massive pattern in $70 \%$ of patients. In pre-stent angioplasty, the lack of such a device was associated to a more frequent occurrence of massive MES patterns during both balloon swelling $(\mathrm{P}=0.004)$ and release $(\mathrm{P}<0.001)$.

Prevalence of massive MES patterns was similar in both CEA and CAS groups $(P=0.3)$. Out of the four preselected key moments in the CEA group, one was associated with such patterns, while in the CAS group, there were four out of seven.
Artifactual signals were more frequent in the CEA group ( $\mathrm{P}$ $<0.01)$. MES registered in the contralateral hemisphere were more frequent in the CAS group ( $\mathrm{P}=0.002$; only in two cases in the CEA group and 14 in CAS).

No association was encountered between MES presentation (and MES massive patterns) and RS ( $\mathrm{P}=0.6)$, nor between use or not of a distal protection device in the CAS group.

\section{Discussion}

As we attend to a historical moment with respect to the debate 
on the most suitable carotid revascularization technique, our study provides a detailed approach to hemodynamic phenomena taking place during the carotid endarterectomy and angioplasty procedures.

As in previous studies, in our series there is a majority of male patients $[3,4,24]$. Since angioplasty is offered in case of contraindication to surgery or clinical instability, the CAS group is remarkably heterogeneous. Although there are more elderly patients, a priori a more vulnerable cohort, in the CAS group, this does not entail a higher prevalence of complications or a worse evolution, unlike previous results in the very old [25]. Vascular risk factors are mostly prevalent in both groups. However, there were more asymptomatic cases in the CEA group and the delay to intervention for both procedures exceeded by far that recommended in clinical practice guidelines $[26,27]$.

On the baseline TCD, a greater number of functioning collateral vessels are shown in the CAS group, which suggests a more precarious hemodynamic situation among these patients. However, baseline (before undergoing the revascularization procedures, as all patients were registered by TCD during procedures) TCD was available for only $48 \%$ of the CEA patients, thus limiting our conclusions on this matter. However, there were no differences regarding the asymmetry in MV or pulsatility between both MCAs, and the hemodynamic reserve, which is surprising given the expected worse hemodynamic situation of CAS patients.

There were several attempts to define different parameters able to explain the hemodynamic changes along the revascularization procedures and their clinical repercussion. TCD provides a functional view in this sense, as we will try to show along this discussion. Concerning hemodynamic reserve, a trend to lower values with increasing degrees of carotid stenosis was observed. The association of diminished hemodynamic reserve with greater baseline MV asymmetry and delayed systolic peak seems also congruent.

Regarding systolic peak flow delay, we did not find any association with the number of collateral vessels or degree of ipsilateral stenosis, which could be explained by the corrective effect of collateral flow. On the contralateral carotid artery, we did find such an association between the degree of stenosis and the systolic peak delay at the MCA of the same side, probably because collateral vessels were not taking part in the maintenance of flow, being supposedly a more stable circulatory bed than the one to be intervened. Furthermore, the inverse correlation observed between the contralateral systolic peak delay and the homolateral carotid stenosis is thought to reflect the contralateral compensatory flow acceleration.

As for collateral vessels, both the number of collaterals and the flow inversion at the ophthalmic artery are related to the degree of stenosis, which suggests a progressive collateral recruitment, once the stenosis becomes hemodynamically significant. We also observed that flow inversion at the ophthalmic artery is encountered when at least other two collateral arteries are patent, thus pointing to a situation of higher hemodynamic risk, although it also depends on the individual variability of the circle of Willis. Moreover, antidromic ophthalmic artery is even more frequent in presence of a significant contralateral carotid stenosis.
Spencer demonstrated that patients with an MCA flow velocity $<40 \%$ during carotid clamping compared to the baseline were at a higher risk of developing neurological deficits after surgery, due to hypoperfusion [28]. Ackerstaff et al proposed a model for the surgical stroke risk in patients with $\geq$ $70 \%$ symptomatic carotid stenosis, involving microemboli detection during dissection and clamping, a $\geq 90 \%$ decrease of MCA systolic peak during clamping and $\geq 100 \%$ increase in PI at clamping release [29]. Orlandi et al performed TCD monitoring of CAS procedures, demonstrating that baseline MCA velocity was significantly lower in patients suffering a neurological deficit after intervention [30]. Our study cannot establish conclusions in the same way of the previous authors, due to the small sample size and low morbidity, but it is able to define parameters suggestive of a precarious hemodynamic situation. These parameters are not affected by hemodynamic changes among different phases of the procedures which were also studied comparing each other, but they are influenced by the global changes and baseline flow asymmetries.

A detailed analysis of data on hemodynamic changes during both revascularization procedures allows distinguishing two groups of patients according to the changes in MV after intervention. There is a trend to more marked changes in CAS patients, which may be explained by their baseline characteristics rather than the technique itself. Although such trend did not attain statistical significance, probably due to the small sample size, only two CEA patients fall in the group defined by a more marked change. All patients with orthodromic ophthalmic artery experiment changes in MV lower than $40 \%$, again pointing to antidromic ophthalmic artery as a predictor of hemodynamic precariousness. Previous studies have encountered that collateral support through this artery indicates poor prognosis [31, 32]. Preocclusive carotid stenosis $(\geq 95 \%)$ is also associated to a more marked MV change, probably due to vasoparalysis and exhaustion of compensation mechanisms, and consequent poor adaptability to abrupt changes in blood flow.

Previous works have found CAS procedure to be associated to a greater number of both MES [33] and DWI-MRI hyperintense signals within $24 \mathrm{~h}$ of the intervention [34-37]. However, results are conflicting regarding the relationship between MES number and stroke risk [33, 34, 38-42]. In our series, we did not find differences between both techniques $(\mathrm{P}=0.3)$.

Concerning CEA, although surgeons focus mainly on prevention of hemodynamic failure during clamping, most strokes related to surgery are of thromboembolic cause [43]. In our series, dissection and clamping are associated to scarce MES register, unlike previous works [41], while clamping release is shown to be the most emboligenic phase. Shunt, a step associated to a great number of MES [41], was employed in only one patient in our study. Handling of the vessels during hemostasis at the end of the procedure is, in our study, the second phase according to MES register, although there is a majority of mild patterns. Other works have not reported similar results on MES during this phase.

Distal protection devices are an important yet controversial issue regarding CAS procedures. Their employment has been found to be associated to lower morbidity rates [44, 45]. In our series, we found a lower frequency of massive patterns during the phase of angioplasty before stent placement in asso- 
ciation to the employment of such devices, but no differences were found in other phases. On the other hand, massive MES patterns were registered during its opening. Previous studies have found a higher number of MES in relation to the use of these devices, and no differences in hyperintense signals in MR-DWI [46, 47]. So, there is not an unequivocal superiority in terms of stroke risk or embolization to support the use of protection device undoubtedly.

Artifactual signals are more common in the CEA group, probably because of the greater technical difficulty, due to less space available, hyperextension and cephalic rotation needed for surgery and interferences produced by electrocautery. In CAS groups, the main artifact source is contrast, whose signal is similar to that of MES. Contralateral emboli detection was more common in the CAS group $(\mathrm{P}=0.002)$. This might be a consequence of navigation through the aortic arch and arterial cannulation [34, 40, 48-50], and it is not described for CEA. The two patients in the CEA group with contralateral MES register in our series had an occlusive contralateral carotid artery, so MES would come from the intervened side through interhemispheric collateral vessels of the circle of Willis.

Therefore, this study has some weakness that impedes to deduce absolute conclusions about what happens in cerebral hemodynamics. Its sample is limited, sometimes heterogeneous and each patient has some particularities in the vessels that make difficult to conclude stable and reproducible situations. Nonetheless, despite of these limits, we were able to obtain some statistically relationship between several parameters that point to uncertain hemodynamic situations, although in our series morbidity was scarce and we were not able to show a truth risk of stroke, RS or other complications according to those parameters.

\section{Conclusions}

TCD is a useful tool for the overall assessment of cerebral hemodynamics, providing information on many different parameters and allowing identifying patients in a precarious situation, both in a basal context and as hemodynamics changes during carotid revascularization.

Impaired cerebral hemodynamic reserve may be a good indicator of precarious hemodynamic situation, but it is dependent on the MV asymmetry between both MCAs and the systolic peak delay. On the other hand, the number of patent collateral vessels increases with the degree of carotid stenosis, but ophthalmic flow inversion only occurs when collateral supply through other vessels becomes insufficient and it is repeatedly found as a higher hemodynamic risk value, as it is absent in preocclusive stenosis, and higher MV asymmetry at baseline patients, who experiment more marked MV increase after revascularization. Despite of these findings, we were not able to show a clinical relevance in terms of interventional complications.

MES register is not associated with a specific revascularization technique or the occurrence of reperfusion symptoms, nor with the employment of a distal protection device in the CAS procedures.

\section{Disclosures}

None.

\section{Declarations}

All procedures followed were in accordance with the ethical standards of the responsible committee on human experimentation (institutional and national) and with the Helsinki Declaration of 1975 , as revised in 2000 , according to the Ethical Committee from the Hospital Universitario Central de Asturias.

\section{References}

1. Bogousslavsky J, Van Melle G, Regli F. The Lausanne Stroke Registry: analysis of 1,000 consecutive patients with first stroke. Stroke. 1988;19(9):1083-1092.

2. Sacco RL. Clinical practice. Extracranial carotid stenosis. N Engl J Med. 2001;345(15):1113-1118.

3. Barnett HJ, Taylor DW, Eliasziw M, Fox AJ, Ferguson GG, Haynes RB, Rankin RN, et al. Benefit of carotid endarterectomy in patients with symptomatic moderate or severe stenosis. North American Symptomatic Carotid Endarterectomy Trial Collaborators. N Engl J Med. 1998;339(20):1415-1425.

4. Randomised trial of endarterectomy for recently symptomatic carotid stenosis: final results of the MRC European Carotid Surgery Trial (ECST). Lancet. 1998;351(9113):1379-1387.

5. Endarterectomy for asymptomatic carotid artery stenosis. Executive Committee for the Asymptomatic Carotid Atherosclerosis Study. JAMA. 1995;273(18):1421-1428.

6. Rothwell PM, Goldstein LB. Carotid endarterectomy for asymptomatic carotid ste-nosis: asymptomatic carotid surgery trial. Stroke. 2004;35(10):2425-2427.

7. Coward LJ, Featherstone RL, Brown MM. Percutaneous transluminal angioplasty and stenting for carotid artery stenosis. Cochrane Database Syst Rev. 2004;(2):CD000515.

8. Bonati LH, Ederle J, McCabe DJ, Dobson J, Featherstone RL, Gaines PA, Beard JD, et al. Long-term risk of carotid restenosis in patients randomly assigned to endovascular treatment or endarterectomy in the Carotid and Vertebral Artery Transluminal Angioplasty Study (CAVATAS): long-term follow-up of a randomised trial. Lancet Neurol. 2009;8(10):908-917.

9. Mas JL, Trinquart L, Leys D, Albucher JF, Rousseau H, Viguier A, Bossavy JP, et al. Endarterectomy Versus Angioplasty in Patients with Symptomatic Severe Carotid Stenosis (EVA-3S) trial: results up to 4 years from a randomised, multicentre trial. Lancet Neurol. 2008;7(10):885-892.

10. Mas JL, Chatellier G, Beyssen B, Branchereau A, Moulin $\mathrm{T}$, Becquemin JP, Larrue V, et al. Endarterectomy versus stenting in patients with symptomatic severe carotid steno-sis. N Engl J Med. 2006;355(16):1660-1671. 
11. Ederle J, Bonati LH, Dobson J, Featherstone RL, Gaines PA, Beard JD, Venables GS, et al. Endovascular treatment with angioplasty or stenting versus endarterectomy in pa-tients with carotid artery stenosis in the Carotid and Vertebral Artery Transluminal Angio-plasty Study (CAVATAS): long-term follow-up of a randomised trial. Lancet Neurol. 2009;8(10):898-907.

12. Brott TG, Hobson RW, 2nd, Howard G, Roubin GS, Clark WM, Brooks W, Mackey A, et al. Stenting versus endarterectomy for treatment of carotid-artery stenosis. N Engl J Med. 2010;363(1):11-23.

13. Yadav JS. Stenting and angioplasty with protection in patients at high risk from endarterectomy: the SAPPHIRE study. Circulation. 2002;106:2986a.

14. Ringleb PA, Allenberg J, Bruckmann H, Eckstein HH, Fraedrich G, Hartmann M, Hennerici M, et al. 30 day results from the SPACE trial of stent-protected angioplasty ver-sus carotid endarterectomy in symptomatic patients: a randomised non-inferiority trial. Lan-cet. 2006;368(9543):1239-1247.

15. Llu X, Xlong Y, Zhou Z, Nlu G, Wang W, Xlao G. China Interventional stroke reg-istry: rationale and study desing. Cerebrovas Dis. 2013;35:349-354.

16. Huber P, Handa J. Effect of contrast material, hypercapnia, hyperventilation, hyper-tonic glucose and papaverine on the diameter of the cerebral arteries. Angiographic determi-nation in man. Invest Radiol. 1967;2(1):17-32.

17. Webster MW, Makaroun MS, Steed DL, Smith HA, Johnson DW, Yonas H. Com-promised cerebral blood flow reactivity is a predictor of stroke in patients with symptomatic carotid artery occlusive disease. J Vasc Surg. 1995;21(2):338-344; discussion 344-335.

18. Markus H, Cullinane M. Severely impaired cerebrovascular reactivity predicts stroke and TIA risk in patients with carotid artery stenosis and occlusion. Brain. 2001;124(Pt 3):457-467.

19. Aaslid R, Markwalder TM, Nornes H. Noninvasive transcranial Doppler ultrasound recording of flow velocity in basal cerebral arteries. J Neurosurg. 1982;57(6):769-774.

20. Assessment: transcranial Doppler. Report of the American Academy of Neurology, Therapeutics and Technology Assessment Subcommittee. Neurology. 1990;40(4):680681.

21. Sloan MA, Alexandrov AV, Tegeler CH, Spencer MP, Caplan LR, Feldmann E, Wechsler LR, et al. Assessment: transcranial Doppler ultrasonography: report of the Thera-peutics and Technology Assessment Subcommittee of the American Academy of Neurolo-gy. Neurology. 2004;62(9):1468-1481.

22. Markus HS, Harrison MJ. Estimation of cerebrovascular reactivity using transcranial Doppler, including the use of breath-holding as the vasodilatory stimulus. Stroke. 1992;23(5):668-673.

23. Buczek J, Karlinski M, Kobayashi A, Bialek P, Czlonkowska A. Hyperperfusion syndrome after carotid endarterectomy and carotid stenting. Cerebrovasc Dis. 2013;35(6):531-537.

24. Rothwell PM, Eliasziw M, Gutnikov SA, Warlow CP,
Barnett HJ. Endarterectomy for symptomatic carotid stenosis in relation to clinical subgroups and timing of surgery. Lancet. 2004;363(9413):915-924.

25. Grant A, White C, Ansel G, Bacharach M, Metzger C, Velez C. Safety and efficacy of carotid stenting in the very elderly. Catheter Cardiovasc Interv. 2010;75(5):651-655.

26. Guidelines for management of ischaemic stroke and transient ischaemic attack 2008. Cerebrovasc Dis. 2008;25(5):457-507.

27. The Lancet N. Time is brain for carotid endarterectomy. Lancet Neurol. 2010;9(9):841.

28. Ghali R, Palazzo EG, Rodriguez DI, Zammit M, Loudenback DL, DeMuth RP, Spencer MP, et al. Transcranial Doppler intraoperative monitoring during carotid endarter-ectomy: experience with regional or general anesthesia, with and without shunting. Ann Vasc Surg. 1997;11(1):9-13.

29. Ackerstaff RG, Moons KG, van de Vlasakker CJ, Moll FL, Vermeulen FE, Algra A, Spencer MP. Association of intraoperative transcranial doppler monitoring variables with stroke from carotid endarterectomy. Stroke. 2000;31(8):1817-1823.

30. Orlandi G, Fanucchi S, Gallerini S, Sonnoli C, Cosottini M, Puglioli M, Sartucci F, et al. Impaired clearance of microemboli and cerebrovascular symptoms during carotid stenting procedures. Arch Neurol. 2005;62(8):1208-1211.

31. Schneider PA, Rossman ME, Bernstein EF, Ringelstein EB, Otis SM. Noninvasive assessment of cerebral collateral blood supply through the ophthalmic artery. Stroke. 1991;22(1):31-36.

32. Tatemichi TK, Chamorro A, Petty GW, Khandji A, Oropeza LA, Duterte DI, Mohr JP. Hemodynamic role of ophthalmic artery collateral in internal carotid artery occlusion. Neurology. 1990;40(3 Pt 1):461-464.

33. Jordan WD Jr, Voellinger DC, Doblar DD, Plyushcheva NP, Fisher WS, McDowell HA. Microemboli detected by transcraneal Doppler monitoring in patients during carotid angioplasty versus carotid Endarterectomy. Eur J Vasc Endovasc Surg. 2000;19:56-61.

34. Muller M, Reiche W, Langenscheidt P, Hassfeld J, Hagen T. Ischemia after carotid endarterectomy: comparison between transcranial Doppler sonography and diffusion-weighted MR imaging. AJNR Am J Neuroradiol. 2000;21(1):47-54.

35. Barth A, Remonda L, Lovblad KO, Schroth G, Seiler RW. Silent cerebral ischemia detected by diffusionweighted MRI after carotid endarterectomy. Stroke. 2000;31(8):1824-1828.

36. Pinero P, Gonzalez A, Mayol A, Martinez E, GonzalezMarcos JR, Boza F, Cayuela A, et al. Silent ischemia after neuroprotected percutaneous carotid stenting: a diffusion-weighted MRI study. AJNR Am J Neuroradiol. 2006;27(6):1338-1345.

37. van Heesewijk HP, Vos JA, Louwerse ES, Van Den Berg JC, Overtoom TT, Ernst SM, Mauser HW, et al. New brain lesions at MR imaging after carotid angioplasty and stent placement. Radiology. 2002;224(2):361-365.

38. Transcranial Doppler monitoring in angioplasty and stenting of the carotid bifurca-tion. J Endovasc Ther. 
2003;10(4):702-710.

39. Cantelmo NL, Babikian VL, Samaraweera RN, Gordon JK, Pochay VE, Winter MR. Cerebral microembolism and ischemic changes associated with carotid endarterectomy. J Vasc Surg. 1998;27(6):1024-1030; discussion 1030-1021.

40. Schnaudigel S, Groschel K, Pilgram SM, Kastrup A. New brain lesions after carotid stenting versus carotid endarterectomy: a systematic review of the literature. Stroke. 2008;39(6): 1911-1919.

41. Wolf O, Heider P, Heinz M, Poppert H, Sander D, Greil $\mathrm{O}$, Weiss W, et al. Micro-embolic signals detected by transcranial Doppler sonography during carotid endarterectomy and correlation with serial diffusion-weighted imaging. Stroke. 2004;35(11):e373-375.

42. Hao Q, Leung WH, Leung C, Mok CT, Leung H, Soo Y, Chen XY, et al. The signif-icance of microembolic signals and new cerebral infarcts on the progression of neurological deficit in acute stroke patients with large artery stenosis. Cerebrovasc Dis. 2010;29(5):424-430.

43. Steed DL, Peitzman AB, Grundy BL, Webster MW. Causes of stroke in carotid endarterectomy. Surgery. 1982;92(4):634-641.

44. Massop D, Dave R, Metzger C, Bachinsky W, Solis M, Shah R, Schultz G, et al. Stenting and angioplasty with protection in patients at high-risk for endarterectomy: SAP-PHIRE Worldwide Registry first 2,001 patients.
Catheter Cardiovasc Interv. 2009;73(2):129-136.

45. Schreiber TL, Strickman N, Davis T, Kumar V, Mishkel G, Foster M, Donohoe D, et al. Carotid artery stenting with emboli protection surveillance study: outcomes at 1 year. J Am Coll Cardiol. 2010;56(1):49-57.

46. Vos JA, van den Berg JC, Ernst SM, Suttorp MJ, Overtoom TT, Mauser HW, Vogels OJ, et al. Carotid angioplasty and stent placement: comparison of transcranial Doppler US data and clinical outcome with and without filtering cerebral protection devices in 509 pa-tients. Radiology. 2005;234(2):493-499.

47. Macdonald S, Evans DH, Griffiths PD, McKevitt FM, Venables GS, Cleveland TJ, Gaines PA. Filter-protected versus unprotected carotid artery stenting: a randomised trial. Cerebrovasc Dis. 2010;29(3):282-289.

48. Faraglia V, Palombo G, Stella N, Taurino M, Iocca ML, Romano A, Bozzao A. Cer-ebral embolization in patients undergoing protected carotid-artery stenting and carotid sur-gery. J Cardiovasc Surg (Torino). 2007;48(6):683688.

49. Borges MA, Taylor RL, Weisel RD, Kulkarni G, Benaroia M, Rao V. Decreased cerebral emboli during distal aortic arch cannulation: A reandomized clinical trial. J Torac Cardiovasc Surg. 1999;118:740-745.

50. Georgiadis D, Siebler M. Detection of microembolic signals with transcranial Dop-pler ultrasound. Front Neurol Neurosci. 2006;21:194-205. 